05

\title{
Лазерная генерация коллоидных кремниевых наночастиц, легированных серой и углеродом
}

\author{
() А.А. Настулявичус ${ }^{1}$, С.И. Кудряшов ${ }^{1,2}$, Н.А. Смирнов ${ }^{1}$, Р.А. Хмельницкий ${ }^{1}$, А.А. Руденко ${ }^{1}$, \\ Н.Н. Мельник ${ }^{1}$, Д.А. Кириленко ${ }^{3}$, П.Н. Брунков ${ }^{3}$, А.А. Ионин ${ }^{1}$ \\ ${ }^{1}$ Физический институт имени П.Н. Лебедева РАН, \\ 119333 Москва, Россия \\ 2 Университет ИТМО, \\ 197101 Санкт-Петербург, Россия \\ ${ }^{3}$ ФТИ им. А.Ф. Иофрфе РАН, \\ 194021 Санкт-Петербург, Россия \\ e-mail: ganuary_moon@mail.ru
}

Поступила в редакцию 21.01.2020 г.

В окончательной редакции 21.02.2020 г.

Принята к публикации 28.02.2020 г.

\begin{abstract}
Методом наносекундной лазерной абляции кремния в жидком сероуглероде были получены уникальные кремниевые наночастицы, легированные серой и углеродом, а также частично окисленные. Была проведена их детальная структурная, химическая и оптическая характеризация методами сканирующей и просвечивающей электронной микроскопии, ИК спектроскопии, энерго-дисперсионной рентгеновской спектроскопии и спектроскопии комбинационного рассеяния света. Исследования показали, что содержание серы в частицах составляет порядка 1 ат.\%, благодаря чему они демонстрируют существенное поглощение в среднем ИК диапазоне.
\end{abstract}

Ключевые слова: кремний, лазерная абляция, плазма, легирование серой, кремниевые наночастицы.

DOI: $10.21883 / O S .2020 .07 .49558 .61-20$

\section{Введение}

Наночастицы с момента их появления широко исследуются и повсеместно используются во многих областях науки и техники, включая микробиологию, медицину и фармацевтику, солнечную энергетику ит.д. [1,2]. Большой интерес к ним обусловлен благодаря их уникальным химическим, физическим, оптическим и каталитическим свойствам. Например, магнитные наночастицы используются для таких приложений, как диагностическая визуализация [3], в обработке стоков и удалении ионов металлов [4]. Важным классом являются липосомы - сферические пузырьки из двойного слоя липидов [5], которые используются для адресной доставки лекарств $[6,7]$. Наночастицы также применяются в косметологии [8]. Например, наночастицы оксида цинка используются для изготовления солнцезащитных средств $[9,10]$. Наночастицы таких материалов как графен, диоксид кремния, серебро часто используются в качестве наполнителей для пищевых упаковок, изготовляемых из полимеров [11]. Многие металлические наночастицы обладают антибактериальными свойствами [12]. Также известно, что селеновым и кремниевым наночастицам присуща антибактериальная активность [13-15]. В свою очередь, кремниевые частицы имеют особенно большое число применений. Полученные в результате фотоиндуцированной прививочной полимеризации акриловой кислоты на поверхности кремниевых наночастиц поверхностно-модифицированные наночастицы используются в качестве биологических меток для визуализации клеток [16]. Частицы отличаются биосовместимостью, имеют низкую цито- и генотоксичность $[17,18]$. Помимо этого они полезны для фотодинамической терапии на кремниевых наноструктурах [19,20]. Монокристаллические наночастицы кремния диаметром в несколько десятков нанометров могут быть использованы в основе создания электронных устройств, состоящих из одиночных наночастиц [21]. Наночастицы пористого кремния успешно используются в качестве анодов для литийионных аккумуляторов с высокими эксплуатационными характеристиками [22].

Известно, что кремниевые наночастицы используются для улучшения характеристик солнечных элементов. В работе [23] рассматриваются несколько механизмов, ответственных за это улучшение: например, преобразование длины волны в результате радиационной рекомбинации фотовозбужденных экситонов, которая позволяет солнечному элементу поглощать больше солнечного света; разделение экситонного заряда и перенос заряда в пленке (верхний солнечный элемент) или улучшенное сцепление и распространение света (антиотражающие покрытия).

Для синтеза наночастиц используются химические, физические, биологические методы [24]. Стоит выделить лазерные методы, обладающие многими преимуществами, среди которых можно выделить простоту получения, так как не требуется сложной экспериментальной 
установки, длительную стабильность полученных наночастиц, отсутствие загрязнений $[25,26]$.

В настоящей работе с помощью метода лазерной абляции в среде жидкого сероуглерода были получены наночастицы кремния, легированные серой и углеродом, а также частично окисленные. За счет легирования предполагалось увеличить поглощение кремниевых наночастиц в ИК области, что в дальнейшем может позволить более продуктивно использовать их в целях тераностики, а также для увеличения эффективности работы солнечных батарей.

\section{Материалы и методы}

Наночастицы кремния были получены в среде жидкого сероуглерода путем абляции оптически полированной пластины кремния $n$-типа (111) с помощью излучения волоконного лазерного маркера HTF MARK (Булат) на ионах $\mathrm{Yb}^{3+}$ с длиной волны $1064 \mathrm{~nm}$, длительностью импульса на полувысоте $120 \mathrm{~ns}$, максимальной энергией в импульсе $1 \mathrm{~mJ}$ и частотой повторения импульсов до $80 \mathrm{kHz}$ (рис. 1).

Для лазерной генерации кремниевых наночастиц непосредственно использовалось лазерное излучение с энергией $0.5 \mathrm{~mJ}$, частотой $20 \mathrm{kHz}$ и скоростью сканирования $100 \mathrm{~mm} / \mathrm{s}$ ( $\approx 6$ импульсов в точку). Для каждого образца выбирался участок $10 \times 10 \mathrm{~mm}$, на котором производилось сканирование в один проход. Пластина кремния размещалась в стеклянной кювете и заливалась жидким сероуглеродом, высота которого над поверхностью пластины составляла $\approx 3 \mathrm{~mm}$. Кювета накрывалась стеклянной крышкой в целях исключения возгорания и выплескивания жидкости во время кипения в ходе лазерного облучения. Излучение фокусировалось гальваносканером с фокусным расстоянием объектива $160 \mathrm{~mm}$, минимальный размер пятна фокусировки составлял $D_{0} \approx 27 \mu \mathrm{m}$.

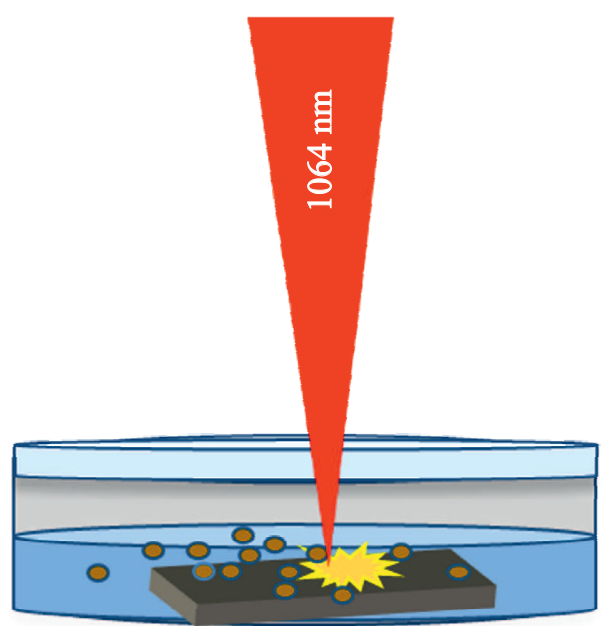

Рис. 1. Схема эксперимента.

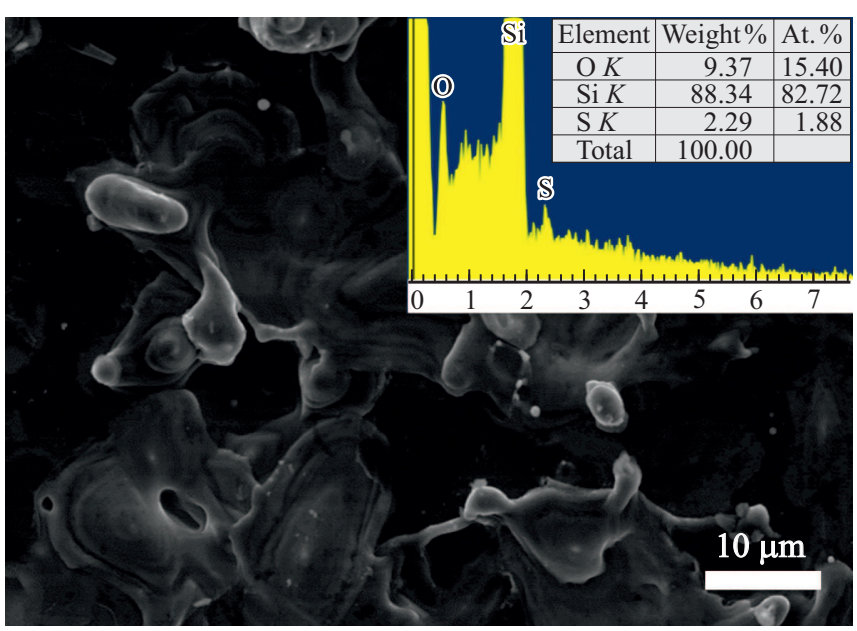

Рис. 2. СЭМ-визуализация поверхности кремния после лазерной обработки. Вставка: ЭДРС-спектр и результаты его анализа.

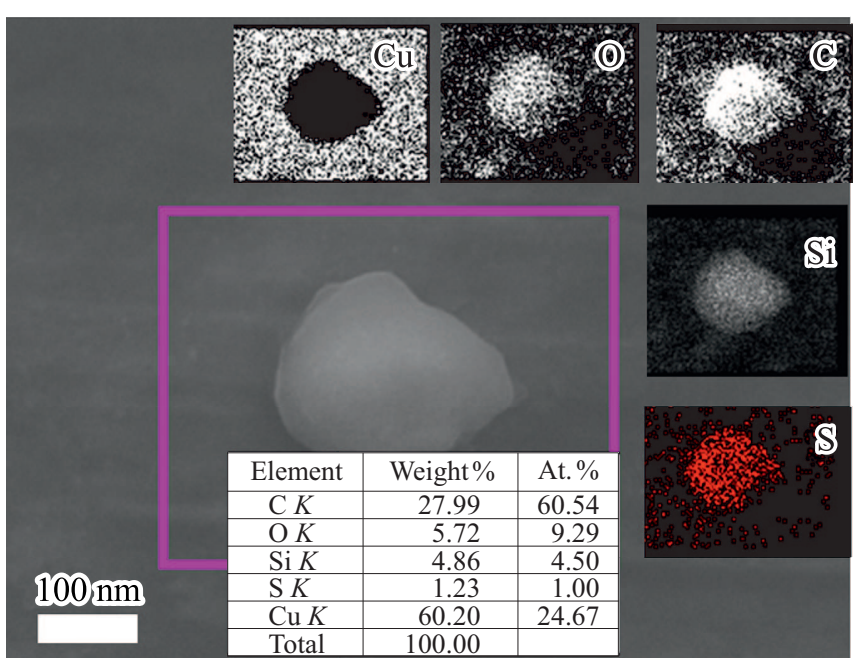

Рис. 3. СЭМ-визуализация кремниевой наночастицы и результаты ее элементного ЭДРС-анализа. Вставка: ЭДРС-карты основных элементов.

Лазерная абляция была связана с формированием эрозионной субкритической лазерной плазмы абляционного факела. Диссоциация и ионизация продуктов абляции в эрозионной плазме позволяют в фазе схлопывания пузыря обеспечить агрегацию коллоидных наночастиц в жидкости с продуктами конденсации из рекомбинировавшей и расширившейся плазмы [27]. Этот механизм обеспечивает сильное химическое взаимодействие продуктов конденсации из плазмы и растворителя. Сильные высокотемпературные взаимодействия между продуктами абляции $\mathrm{Si}$ и парами растворителя $\mathrm{CS}_{2}$ приводят к разложению молекул растворителя.

Визуализация поверхности кремния после лазерной обработки и продуктов абляции (наночастиц) производилась с помощью сканирующего электронного микроскопа (СЭМ, JEOL 7001F, Япония). Для этого колло- 


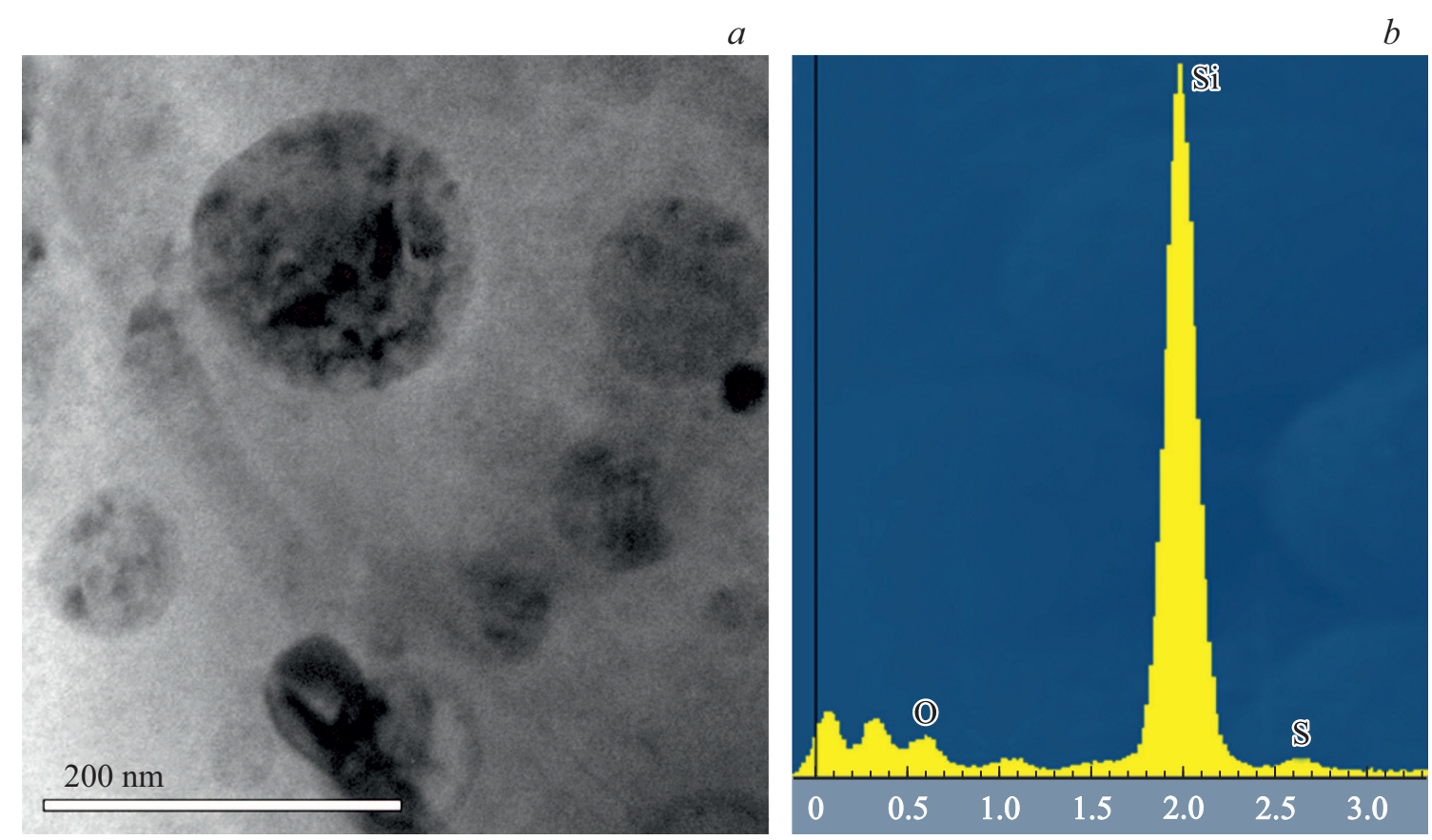

Рис. 4. ПЭМ-визуализация легированных наночастиц (a), ЭДРС-спектр (b).

идные наночастицы высаживались и высушивались на медной пластинке. Для визуализации наночастиц также использовался просвечивающий электронный микроскоп (ПЭМ, JEM-2100F, Jeol, Япония). Химический состав исследовался с помощью энергодисперсионного рентгеноспектрального химического микроанализа (ЭДРС) с использованием модуля INCA (Oxford Instruments) электронного микроскопа. Для спектральных исследований использовался ИК спектрометр (V-70 (Bruker)) и микроскоп комбинационного рассеяния света (U-1000, Jobin Yvon).

\section{Результаты и обсуждение}

После многоимпульсного лазерного облучения на поверхности кремния видны оплавленные участки развитого микрорельефа, а также отдельно лежащие наночастицы субмикронных размеров (рис. 2). ЭДРС-анализ показал, что поверхность кремния легирована серой, содержание которой составляет примерно 2 at.\%, что довольно характерно для данного метода легирования кремния. Исходя из элементного состава также видно, что поверхность существенно окислена ( $\approx 15.40$ at.\%).

Продукты абляции - коллоидные легированные серой и углеродом кремниевые наночастицы - после окончания лазерного воздействия сразу же отделялись и высаживались на различные подложки для дальнейших исследований. Для СЭМ-анализа наночастицы были высажены на поверхность медной пластины. Выяснилось, что частицы преимущественно имеют сферическую форму. Наблюдается большой разброс по размерам. Сред- ний диаметр частиц лежит в диапазоне от 5 до $700 \mathrm{~nm}$, но за счет центрифугирования можно отделить наночастицы до $100 \mathrm{~nm}$, которые можно использовать в целях тераностики. На рис. 3 показаны карты распределения химических элементов для частиц на выбранной области.

ЭДРС-анализ показал, что содержание серы в наночастицах составляет примерно 1 at.\%, что проявляется в наличии сильного широкополосного непрерывного и структурного поглощения среднего ИК диапазона $(3-10 \mu \mathrm{m})$, связанного с формированием примесных мелких и глубоких кластерных центров серы различных типов. Также характерно большое содержание углерода $(\approx 60 \%)$ и небольшое окисление $(\approx 10 \%)$. Видно, что медь экранируется в области нахождения кремниевой наночастицы (под ней), размер которой составляет порядка $120 \mathrm{~nm}$. В самой частице также распределены сера, кислород и углерод.

Для ПЭМ-исследований наночастицы были высажены на углеродную сетку. Исследования показали, что частицы имеют аморфно-кристаллическую структуру, а также существенное содержание углерода, кислорода и серы (рис. 4).

Для ИК спектроскопии коллоидные наночастицы в несколько слоев (толщина покрытия порядка $200 \mathrm{~nm}$ ) высаживались на подложку $\mathrm{CaF}_{2}$, спектр которой также измерялся. Спектры были сняты в диапазоне 400-7500 $\mathrm{cm}^{-1}$ (рис. 5, a). У образца наблюдается поглощение в диапазоне $1000-1100 \mathrm{~cm}^{-1}$, связанное с валентными колебаниями $\mathrm{Si}-\mathrm{O}-\mathrm{Si}$-связей. Основной компонент $\mathrm{Si}$ представлен в своих оксидных формах ( $\mathrm{SiO}$ 

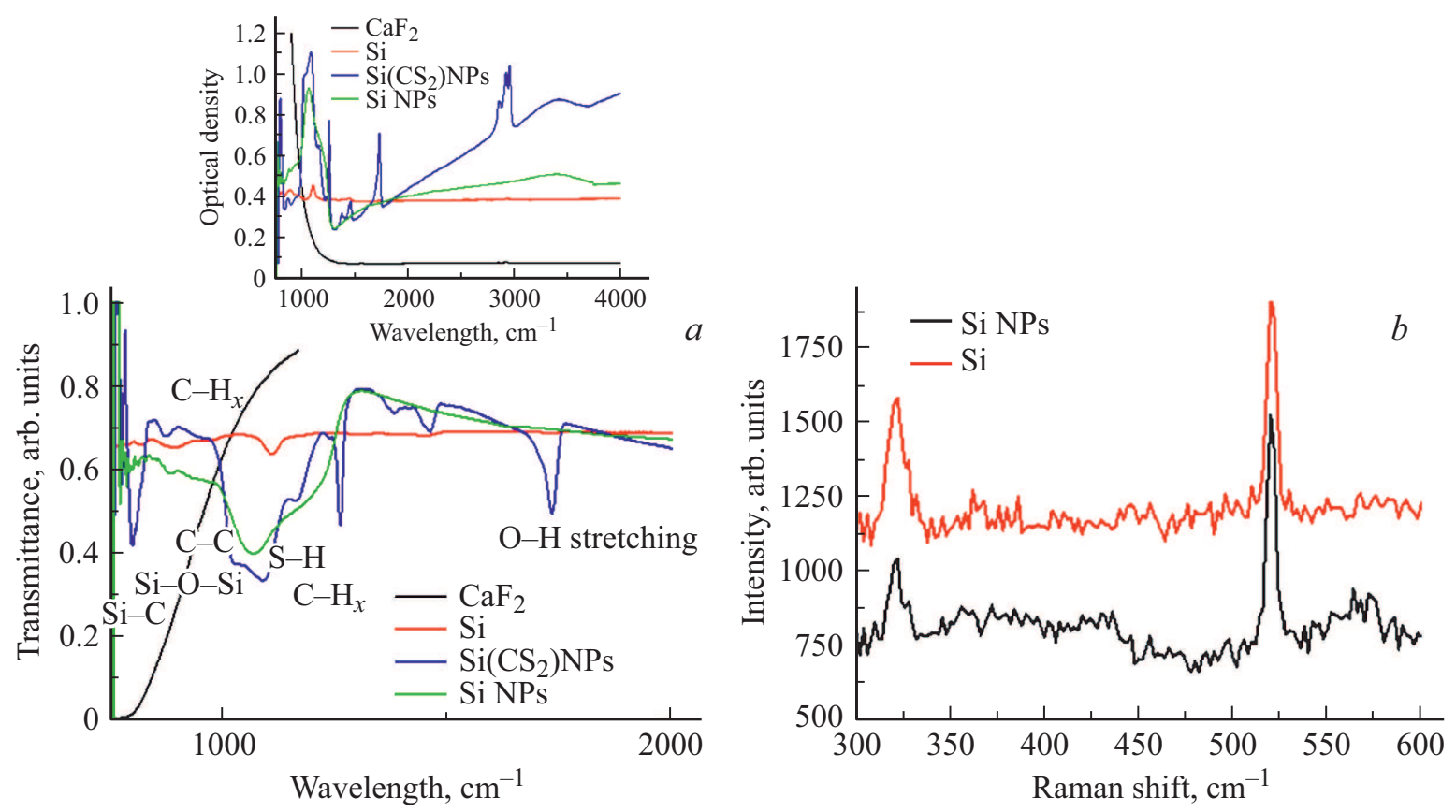

Рис. 5. ИК спектр пропускания $(a)$ и рамановский спектр $(b)$. Вставка: оптическая плотность образцов: подложки СаF 2 , кремниевой пластины, кремниевых наночастиц и легированных наночастиц, высаженных на подложку $\mathrm{CaF}_{2}$.

и $\left.\mathrm{SiO}_{2}\right)$. Также по графику видно присутствие органических соединений с $\mathrm{Si}-\mathrm{C}$-связью, таких как $\mathrm{SiC}_{x} \mathrm{H}_{y} \mathrm{O}_{z}$. $\mathrm{B}$ спектре для кремниевых наночастиц, полученных в дистиллированной воде, нет связей $\mathrm{S}-\mathrm{H}$ и $\mathrm{C}-\mathrm{H}_{x}$. Для легированных кремниевых наночастиц в спектральном диапазоне $1-12 \mu \mathrm{m}$ характерно меньшее пропускание и соответственно большее поглощение по сравнению не только с подложкой, но и с объемной полированной кремниевой пластиной.

Согласно данным спектроскопии комбинационного рассеяния, на рис. 5, $b$ виден характерный пик для кристаллического кремния в области $521 \mathrm{~cm}^{-1}$. Для легированных частиц заметно небольшое смещение в коротковолновую область, которое может быть связано с присутствием наночастиц с размерами $<10 \mathrm{~nm}$.

\section{Заключение}

В ходе работы в результате лазерного абляционного процесса, опосредованного плазмой и возникновением пузырей, были получены уникальные легированные серой и углеродом, частично окисленные кремниевые наночастицы сферической формы с размерами в диапазоне от 5 до $700 \mathrm{~nm}$. Содержание серы в полученных частицах составляет порядка 1 at.\%, что приводит к существенному поглощению в ИК области и представляет интерес для оптоэлектронных и биомедицинских применений.

\section{Финансирование работы}

Исследование выполнено при поддержке Российского фонда фундаментальных исследований в рамках научных проектов № 19-32-50047, № 18-29-20022 и Программы 14П президиума РАН, а также гранта Министерства науки и высшего образования для университета ИТМО (проект 074-U01, позиция С.И.К.).

\section{Конфликт интересов}

Авторы заявляют, что у них нет конфликта интересов.

\section{Список литературы}

[1] O'Farrell N., Houlton A., Horrocks B.R. // Intern. J. Nanomedicine. 2006. V. 1. N 4. P. 451. doi 10.2147/nano.2006.1.4.451

[2] Zhang L., Gu F.X., Chan J.M., Wang A.Z., Langer R.S., Farokhzad O.C. // Clinical Pharmacology \& Therapeutics. 2008. V. 83. N 5. P. 761. doi 10.1038/sj.clpt.6100400

[3] Kalambur V.S., Han B., Hammer B.E., Shield T.W., Bischof J.C. // Nanotechnology. 2005. V. 16. N 8. P. 1221. doi 10.1088/0957-4484/16/8/041

[4] Vatta L.L., Sanderson R.D., Koch K.R. // Pure and Applied Chemistry. 2006. V. 78. N 9. P. 1793.

doi 10.1351/pac200678091793

[5] Avaneesh Pandey. [Электронный ресурс] Режим доступа: https://www.ibtimes.com/cure-cancer-coating-cellsnanoparticles-may-boost-drug-efficiency-2511271 
[6] Гуляев Ю.В., Черепенин В.А., Вдовин В.А., Таранов И.В., Ярославов А.А., Ким В.П., Хомутов Г.Б. // Радиотехника и электроника. 2015. Т. 60. № 10. С. 1051. doi $10.7868 / \mathrm{S} 0033849415100034$

[7] Kamaly N., Miller A.D. // Intern. J. Molecular Sciences. 2010. V. 11. N 4. P. 1759. doi 10.3390/ijms 11041759

[8] Niska K., Zielinska E., Radomski M.W., InkielewiczStepniak I. // Chemico-biological Interactions. 2018. V. 295. P. 38. doi 10.1016/j.cbi.2017.06.018

[9] Yadav A., Prasad V., Kathe A.A., Raj S., Yadav D., Sundaramoorthy C., Vigneshwaran N. // Bulletin of Materials Science. 2006. V. 29. N 6. P. 641. doi 10.1007/s12034-0060017-y

[10] Becheri A., Dürr M., Nostro P.L., Baglioni P. // J. Nanoparticle Research. 2008. V. 10. N 4. P. 679. doi 10.1007/s11051-0079318-3

[11] Rezić I., Haramina T., Rezić T. Metal Nanoparticles and Carbon Nanotubes.perfect Antimicrobial Nano-fillers in Polymer-based Food Packaging Materials. Food Packaging. Academic Press, 2017. P. 497. doi 10.1016/B978-0-12804302-8.00015-7

[12] Slavin Y.N., Asnis J., Häfeli U.O., Bach H. // J. Nanobiotechnology. 2017. V. 15. N 1. P. 65. doi 10.1186/s12951-017-0308-z

[13] Nastulyavichus A., Kudryashov S., Smirnov N., Saraeva I., Rudenko A., Tolordava E., Ionin A., Romanova Y., Zayarny D. // Applied Surface Science. 2019. V. 469. P. 220. doi 10.1016/j.apsusc.2018.11.011

[14] Ionin A.A., Ivanova A.K., Khmel'nitskii R.A., Klevkov Y.V., Kudryashov S.I., Levchenko A.O., Nastulyavichus A.A., Rudenko A.A., Saraeva I.N., Smirnov N.A., Zayarny D.A. // Laser Physics Letters. 2017. V. 15. N 1. P. 015604. doi 10.1088/1612-202X/aa897f

[15] Smirnov N.A., Kudryashov S.I., Nastulyavichus A.A., Rudenko A.A., Saraeva I.N., Tolordava E.R., Gonchukov S.A., Romanova Y.M., Ionin A.A., Zayarny D.A. // Laser Physics Letters. 2018. V. 15. N 10. P. 105602. doi 10.1088/1612$202 \mathrm{X} / \mathrm{aad} 853$

[16] Li Z.F., Ruckenstein E. // Nano Letters. 2004. V. 4. N 8. P. 1463 . doi $10.1021 / \mathrm{n} 10492436$

[17] Kempen P.J., Greasley S., Parker K.A., Campbell J.L., Chang H.Y., Jones J.R., Sinclair R., Gambhir S.S., Jokerst J.V. // Theranostics. 2015. V. 5. N 6. P. 631. doi 10.7150/thno.11389

[18] Chatterjee D.K., Fong L.S., Zhang Y. // Advanced Drug Delivery Reviews. 2008. V. 60. N 15. P. 1627. doi 10.1016/j.addr.2008.08.003

[19] Secret E., Maynadier M., Gallud A., Chaix A., Bouffard E., Gary-Bobo M., Marcotte N., Mongin O., El Cheikh K., Hugues V., Auffan M. // Advanced Materials. 2014. V. 26. N 45. P. 7643. doi 10.1002/adma.201403415

[20] Brevet D., Gary-Bobo M., Raehm L., Richeter S., Hocine O., Amro K., Loock B., Couleaud P., Frochot C., Morére A., Maillard P. // Chem. Commun. 2009. V. 12. P. 1475. doi 10.1039/B900427K

[21] Bapat A., Anderson C., Perrey C.R., Carter C.B., Campbell S.A., Kortshagen U. // Plasma Physics and Controlled Fusion. 2004. V. 46. N 12B. P. B97. doi 10.1088/0741$3335 / 46 / 12 \mathrm{~B} / 009$

[22] Ge M., Rong J., Fang X., Zhang A., Lu Y., Zhou C. // Nano Research. 2013. V. 6. N 3. P. 174. doi $10.1007 / \mathrm{s} 12274-013-$ 0293-y
[23] Chowdhury F.I., Alnuaimi A., El-Atab N., Nayfeh M., Nayfeh A. // Solar Energy. 2016. V. 125. P. 332. doi 10.1016/j.solener.2015.12.030

[24] Rajput N. // Intern. J. Advances in Engineering \& Technology. 2015. V. 7. N 6. P. 1806.

[25] Tsuji T., Iryo K., Watanabe N., Tsuji M. // Applied Surface Science. 2002. V. 202. N 1-2. P. 80. doi 10.1016/S01694332(02)00936-4

[26] Dell-Aglio M., Gaudiuso R., De Pascale O., De Giacomo A. // Applied Surface Science. 2015. V. 348. P. 4. doi 10.1016/j.apsusc.2015.01.082

[27] Kudryashov S.I., Samokhvalov A.A., Nastulyavichus A.A., Saraeva I.N., Mikhailovskii V.Y., Ionin A.A., Veiko V.P. // Materials. 2019. V. 12. N 4. P. 562. doi 10.3390/ma12040562 